\title{
MISERABLES O MENTIROSAS. LA PARTICIPACIÓN JUDICIAL Y EL TRATAMIENTO INQUISITORIAL DE LAS MUJERES INDÍGENAS EN LAS CAUSAS POR SOLICITACIÓN (SANTO OFICIO LIMEÑO, SIGLOS XVI-XVII)
}

\author{
MISERABLES OR LIARS. JUDICIAL INVOLVEMENT AND INQUISITORIAL \\ TREATMENT OF INDIGENOUS WOMEN IN CAUSES OF SOLICITATION \\ (THE INQUISITION OF LIMA, XVI-XVII CENTURIES)
}

\author{
Fernanda Molina*
}

\begin{abstract}
Este artículo analiza la participación judicial de las mujeres indígenas, así como el tratamiento que recibieron sus testimonios en las causas de fe por solicitación incoadas por el Santo Oficio limeño entre 1571 y 1610. Si bien la legislación y la práctica inquisitorial tendieron a devaluar o desestimar sus declaraciones, la investigación revela que las voces de estas mujeres fueron determinantes a la hora de fulminar muchas de esas causas. En ese sentido, el trabajo sugiere que los testimonios judiciales nativos constituyeron una fuente de desestabilización no solo de la posición de los doctrineros acusados, sino también del ordenamiento colonial.
\end{abstract}

Palabras claves: Solicitación, testimonios indígenas, Santo Oficio, Virreinato del Perú.

This article analyzes the participation of indigenous women in judicial proceedings, and the treatment that their testimonies received during the claims of solicitation initiated by the Peruvian Inquisition between 1571 and 1610. Although inquisitorial legislation and practice tended to underrate or dismiss their statements, our research shows that the voices of these women were decisive at the time of closing those claims. In that sense, our work suggests that the native judicial testimonies were a source of destabilization, not only of the accused parish priest, but also of the colonial order.

Key words: Solicitation, Indigenous Testimonies; Holy Office; Viceroyalty of Peru.

\section{Introducción}

El 25 de enero de 1569, mediante una Real Cédula, Felipe II ordenaba el establecimiento del Santo Oficio en las jurisdicciones virreinales de México y Perú. Si bien esa disposición tenía como objetivo combatir la "herética pravedad", el inicio de la actividad inquisitorial en los territorios conquistados coincidió con una reorientación de la institución. Por un lado, los inquisidores expandieron su acción hacia nuevos campos de intervención -como el de las transgresiones sexuales-y, por otro, dirigieron sus esfuerzos hacia el disciplinamiento de los denominados "cristianos viejos". Esta reorientación de la política represiva se vería reforzada en América, en la medida en que las poblaciones indígenas estuvieron eximidas de la competencia inquisitorial en virtud de su "simplicidad y cortedad de entendimiento" (Griffiths 1998; 50).
Pero esa disposición no impidió que los indígenas estuvieran ausentes en los tribunales inquisitoriales. Aun cuando no fueron juzgados en calidad de herejes -la persecución de su heterodoxia religiosa quedó a cargo de la jurisdicción episcopal- sí participaron como testigos en algunos procesos judiciales tramitados en ese fuero. Las causas seguidas por solicitación fueron uno de los escenarios en donde las voces indígenas, particularmente las femeninas, pudieron oírse con mayor intensidad ya que, en su condición de confesantes, fueron objeto de los requerimientos amorosos de los denominados "curas solicitantes".

Mediante el análisis de 43 relaciones de causas de fe (en adelante relaciones de causas) tramitadas por ese delito en el Santo Oficio limeño durante 1571 y 1610 , este artículo se propone indagar en la participación judicial de las mujeres indígenas, así como en el tratamiento que sus testimonios recibieron en

* CONICET-UBA. PROHAL, Instituto de Historia Argentina y Americana “Dr. Emilio Ravignani” (IHAYA), Universidad de Buenos Aires. Dirección postal: 25 de mayo 221, $2^{\circ}$ piso (1002). Buenos Aires, Argentina.

Correo electrónico: fernandavmolina@yahoo.com.ar 
el marco de la praxis judicial. Si bien la legislación y la práctica inquisitorial tendieron a devaluar o desestimar sus declaraciones, la investigación revela que las voces femeninas fueron determinantes a la hora de fulminar las causas criminales y, en muchos casos, representaron una fuente de desestabilización del ordenamiento colonial. Aun cuando las relaciones de causas, en tanto dispositivos de poder, son un artefacto procesal adverso a las voces subalternas, constituyen, no obstante, un excelente punto de partida para excavar en las testificaciones nativas, en la medida en que casi la mitad de ellas fueron elaboradas contra "solicitantes de indias".

\section{En el acto de la confesión}

La persecución a la solicitación que de manera sistemática emprenderá la Inquisición española a partir de la segunda mitad del siglo XVI debe interpretarse en el marco del programa de reforma moral de las costumbres que concitó la atención de autoridades eclesiásticas y civiles desde comienzo de siglo. La preocupación derivaba de la proliferación de ciertas prácticas como la bigamia, el adulterio, el amancebamiento o el matrimonio clandestino que no solo se habían convertido en moneda corriente entre los seglares sino que eran avaladas, cuando no practicadas, por los propios eclesiásticos (WiesnerHanks 2001: 109). Los padres conciliares reunidos en Trento entendieron que cualquier programa de reforma que quisiera implementarse debía contemplar a la sexualidad como una de sus asignaturas principales al tiempo que debía dirigirse hacia el disciplinamiento de quienes debían liderar dicho proceso (Haliczer 1998: 58).

Según los tratadistas, la solicitación era el delito que cometían los curas que, por medio de palabras o actos torpes, requerían lascivamente a las penitentes durante la administración del sacramento de la penitencia (Sarrion Mora 2010: 61). La gravedad del delito consistía en que, al tener lugar en el acto de la confesión o próxima a ella, suponía un menosprecio del sacramento, convirtiendo, eventualmente, al solicitante en sospechoso de herejía (Alejandre 1994: 8). La Inquisición española ponderó este último aspecto con el fin de arrogarse la competencia exclusiva sobre el delito -hasta entonces erráticamente conocido por la justicia episcopal- la que obtuvo mediante una bula emitida por Pío IV el 14 de abril de 1561. Sin desestimar el afán dogmático que inspiró la actuación de la institución, es posible que los componentes heréticos presentes en la solicitación así como en otros delitos sexuales que estuvieron bajo su jurisdicción sirvieran de sustento teológico a las políticas de represión sexual que la Inquisición desarrolló en el marco del programa de ordenamiento moral de la sociedad (Molina 2017b).

La represión del delito de solicitación estuvo presente desde los inicios de la actividad inquisitorial peruana, concentrándose en las primeras cuatro décadas de actuación. En el caso de los "solicitantes de indias", la actuación inquisitorial se concentró entre 1571 y 1603 y estuvo modulada por la pesquisa que el comisario Francisco de Angulo realizó en las doctrinas de indios de la Gobernación del Tucumán (Medina 1945: 140, 138; Mateos 1944a: 20, 24; 1944b: 33-37). La preocupación derivaba de los efectos que la "calidad" del personal eclesiástico podía ocasionar a la conversión y conservación de las "almas indígenas". El aislamiento de las doctrinas, las dificultades de comunicación y la laxitud de los mecanismos de control crearon un caldo de cultivo propicio para el abandono de varios aspectos disciplinares. Amparados en la ausencia de control y favorecidos por su posición de poder, muchos clérigos supieron explotar esas concepciones con el fin de reducir sexualmente -con mayor o menor grado de violencia- a las mujeres de origen indígena.

El espacio de la confesión constituyó uno de los escenarios propicios para que los confesores pudieran hacer efectivos sus deseos carnales. Según los cánones conciliares, todos los fieles debían recurrir al sacramento de la penitencia con el fin de recobrar la gracia que habían perdido a causa del pecado. Aunque debían hacerlo todas las veces que fuera necesario, tenían la obligación de confesar sus faltas al menos una vez al año frente a un sacerdote que era la única persona con autoridad para administrar la absolución (Sarrión Mora 2010: 33-35).

La vida litúrgica de las poblaciones indígenas también se ordenó a partir de esa exigencia aunque no estuvo exenta de controversias, en la medida en que la práctica penitencial presuponía la comprensión de varios conceptos que les eran completamente ajenos (Gruzinsky 1991). Esa situación derivó en que, hasta por lo menos el tercer cuarto del siglo $\mathrm{XVI}$, muy pocas personas recurrieran al sacramento $\mathrm{y}$, en el caso de hacerlo, lo hicieran motivadas por las exigencias de los curas de sus doctrinas. También fue frecuente que los doctrineros se quejaran del modo en que los indígenas se acercaban a la confesión. 
Según los informes que regularmente elevaban a sus superiores, los indios no solían "decir verdad", confundían los pecados, no podían enunciarlos en orden, no distinguían entre mortales y veniales, se contradecían en el curso de sus confesiones, etc. (Gruzinsky 1991: 114). En ese escenario, algunas órdenes se mostraron celosas de la administración del sacramento a los indígenas, concibiendo el uso de la confesión general como el instrumento más idóneo para los neófitos (Estenssoro Fuchs 2003: 206-207).

La llegada de los jesuitas (circa 1567) supuso un cambio en la política confesional en la medida en que la comunión y, por tanto, la confesión definieron el carisma de la orden en la flamante provincia peruana (Estenssoro Fuchs 2003: 204). Sin embargo, la confesión indígena lejos estuvo del ideal penitencial que suponía un sujeto confesante contrito capaz de realizar un examen exhaustivo y consciente de sus pecados; la práctica confesional fue una actividad esencialmente colectiva. Era en vísperas de las pascuas cuando el dispositivo de la confesión se ponía en marcha. Los indígenas eran convocados en grupo una semana antes para instruirlos en los preceptos básicos de la penitencia y prepararlos para una confesión ordenada ${ }^{1}$. El día en que se celebraba el sacramento, los contingentes indígenas solían dirigirse a la iglesia de su doctrina o al convento más cercano donde eran recibidos por el doctrinero o un confesor extraordinario designado para tal fin (Lisi 1990: 135). Una vez allí, también en grupo, solían esperar su turno para acceder a la confesión auricular, ahora sí, en un ámbito individual y privado. Basado en su experiencia misional novohispana, así como en su pericia para la elaboración de grabados, el franciscano Diego Valadés (1579: 207) ilustró, mediante pequeñas escenas, las diferentes etapas que componían el sacramento de la penitencia (Ilustración 1).

No obstante, el pasaje del acto colectivo al individual no suponía la privacidad de la práctica. Según se puede colegir de las relaciones de causas analizadas, la confesión solía realizarse al alcance de la vista -cuando no del oído- de los demás penitentes. Una india que depuso contra Hernando de Góngora en 1596 dijo haber visto cómo en el acto de la confesión "el dicho padre avia començado a retoçar y palpar los pecho a la dicha su hermana" 2 . Si bien podemos considerar que tanto la publicidad como el carácter grupal de la confesión fue consecuencia de las condiciones precarias e improvisadas en las que se administró el sacramento, también podríamos sugerir que fue el resultado de la implementación de diversas políticas confesionales que, aun cuando aspiraban a la individualización del penitente, no pudieron prescindir de las formas colectivas de organización nativas.

Como parte del programa de reforma moral, las materias vinculadas a la sexualidad adquirieron un lugar destacado en la práctica penitencial. Los confesionales fueron uno de los instrumentos que permitieron hacer más eficiente y completa esa indagación, especialmente, en el caso de aquellos confesores cuyos conocimientos dogmáticos resultaban rudimentarios. Además, en la medida en que ofrecía preguntas formuladas en las lenguas vernáculas no solo mejoraba la examinación, sino que permitía llevar adelante la confesión sin la intermediación de intérpretes (Lisi 1990: 258; Valenzuela Márquez 2007: 48-49).

En el apartado correspondiente al sexto mandamiento, el Confesionario para los curas de indios (1585) elaborado a instancias del Tercer Concilio Limense (1583) interrogaba a los indígenas acerca de ciertas transgresiones sexuales: "¿estas amancebado? (...) ¿has tenido cuenta con mugeres solteras o casadas? (...) ¿has pecado con alguna doncella? (...) ¿has forzado a alguna muger? (...) ¿has tenido cuenta con alguna parienta tuya? (...) ¿has peccado con mugeres en Iglesia o cimenterio? (...) ¿hasta tenido poluciones voluntarias o tocamientos suzios contigo mismo? (...) ¿has usado del pecado nefando con alguna persona? (...) ¿has usado de bestialidad con algún animal?" (1985: 11-12v). Como se puede observar, el interrogatorio se organizaba a partir de las distintas especies de la lujuria ordenadas por su grado de gravedad ${ }^{3}$. No obstante, este exhaustivo interrogatorio era seguido por una exhortación a los confesores: "no se ha de preguntar de lo dicho mas de lo que probablemente se entiende avra hecho el que confiesa" (1985: 12v). La advertencia ponía de manifiesto una paradoja en materia de confesión: por un lado, la necesidad de que el sexo fuera nombrado con prudencia y, por otro, la obligación de que "todo deb[ía] ser dicho" (Foucault 2006 [1977]: 27-28). La moderación en la examinación no solo estaba motivada por el temor de inducir al confesante a un pecado hasta entonces desconocido -especialmente cuando se trataba de mujeres-, sino también por la necesidad de aquietar las pasiones carnales que en el curso del interrogatorio pudieran aflorar en los propios confesores. 

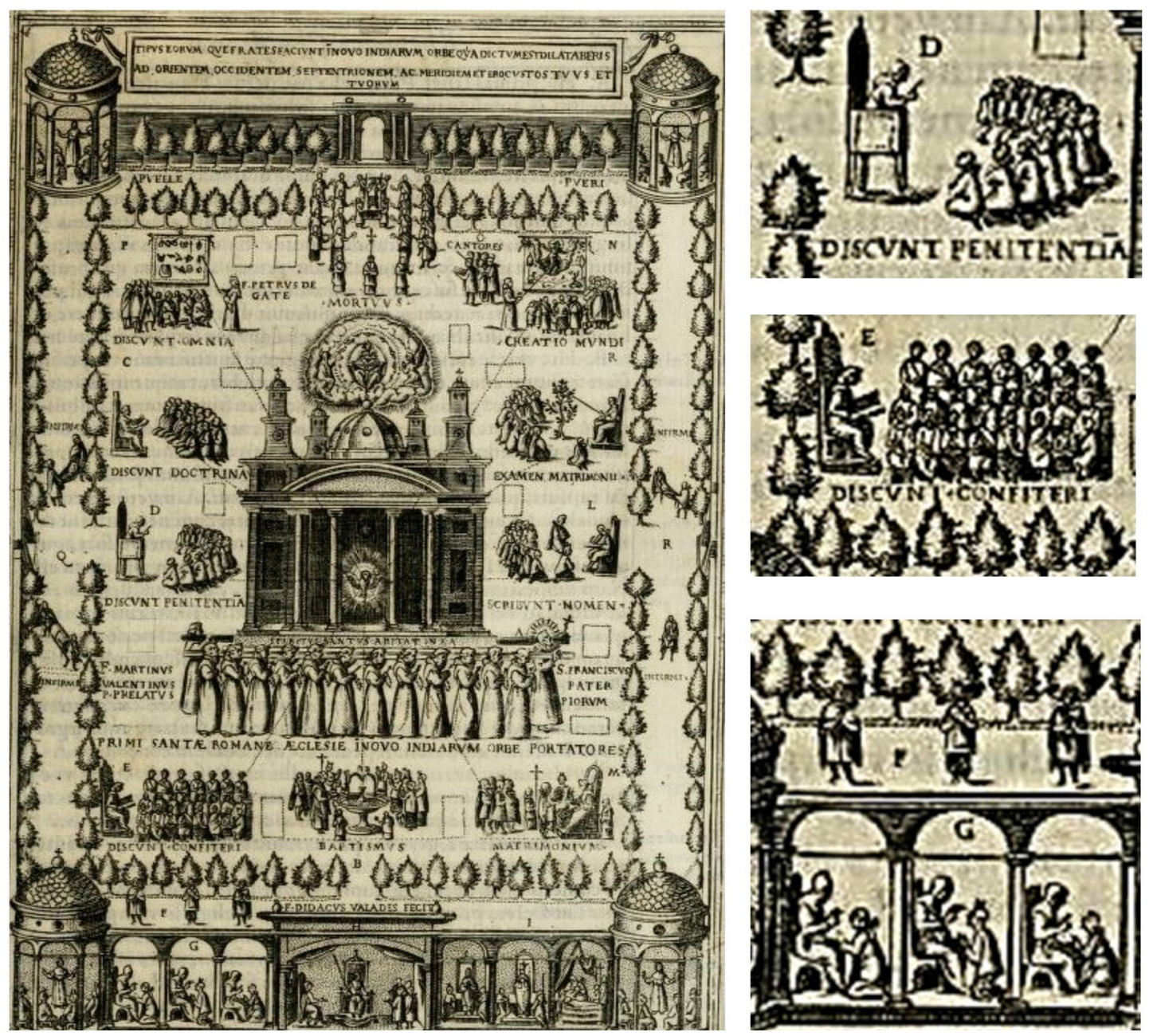

Ilustración 1. Escenas de evangelización franciscana en el Nuevo Mundo. Diego Valadés, Rethorica christiana (1579).

La preocupación expresada en los confesionales no era infundada. Según las relaciones de causa de fe limeñas, los confesores solían solicitar a las penitentes luego de interrogarlas acerca de los pecados de la carne ${ }^{4}$. Si bien muchos de ellos buscaron justificar su comportamiento aludiendo a una supuesta sexualidad indígena disipada, lo cierto es que la castidad o la inexperiencia sexual, muchas veces asociada a la corta edad de las confesantes, tampoco fue obstáculo para desplegar sus conductas lascivas. En efecto, el franciscano Diego de Flores, doctrinero de Trujillo, quien pareció ante los señores inquisidores en la ciudad de Los Reyes en 1610, declaró que confesando a una mujer que por su aspecto le pareció de 9 o 10 años "por curiosidad de saber si estava doncella o no le avia tentado lo pechos sobre la camisa para ver si tenia ya los peçones grandes porque dice es señal de que no están doncellas"5.

El carácter despótico con el que muchos doctrineros desempeñaron su tarea pastoral llevó a Guaman Poma de Ayala a calificarlos de "señores apsolutos y soberbiosos" (1613-1615: 562). En su capítulo dedicado a los "padres", el cronista andino nos ofrece un extenso listado de los abusos cometidos por los curas de las doctrinas, entre los que sobresalen las vejaciones sexuales padecidas por las mujeres indígenas. En el apartado denominado "mala conficion", Guaman Poma denuncia a los malos doctrineros que, con la excusa de administrar el sacramento de la penitencia, conducían a las indias solteras a lugares oscuros o escondidos con "algún efecto y pecado de la fornicación y de pecar con ellas" (Guaman Poma 1615: 577), mientras que a 
la viejas y preñadas las reprendían y maltrataban (Ilustración 2).

Si bien es cierto que las mujeres indígenas contaron con un conjunto de recursos jurídicos con los que podían denunciar este tipo de atropellos, no es menos cierto que al momento de querer canalizar las denuncias muchos mecanismos de poder informales se activaban de manera inmediata. En los casos de solicitación fue habitual que los confesores apelaran a las estrategias de persuasión, intimidación, amenaza o uso abierto de la violencia, con el fin de contener las acusaciones. Sin embargo, los dispositivos de control que organizaron la vida cotidiana en las doctrinas no siempre fueron infranqueables como lo demuestran los testimonios de las mujeres que anidan en los repositorios inquisitoriales.

\section{Excavando los testimonios}

No obstante, los estudios que han indagado en el delito de solicitación en las sociedades coloniales americanas han prestado escasa o nula atención a dichas voces. En muchos casos esa desatención

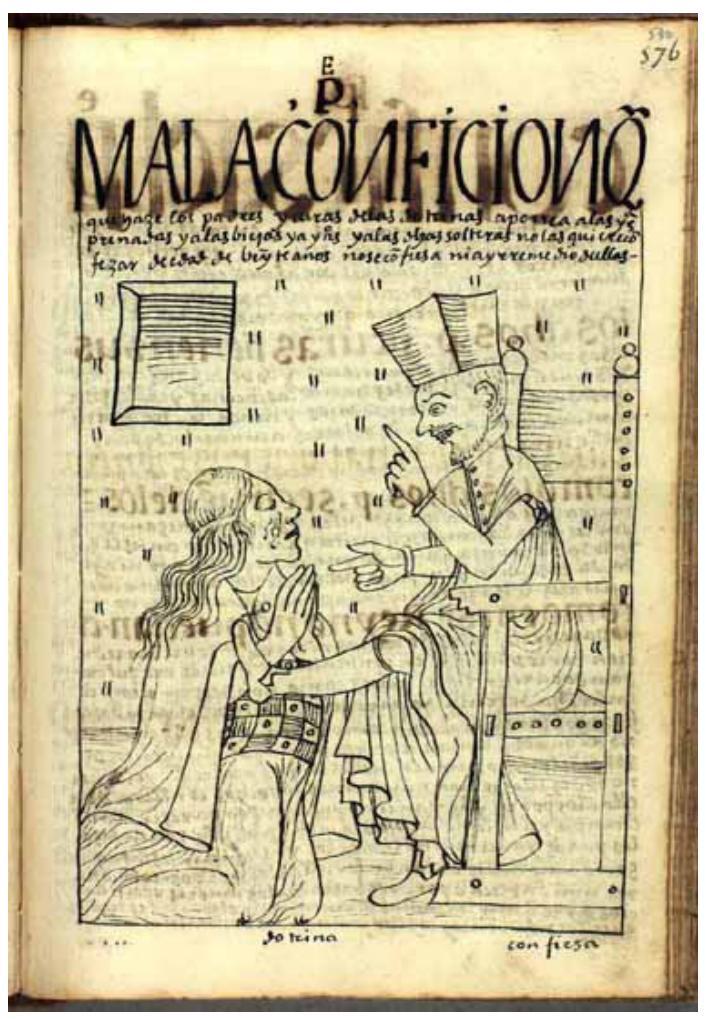

Ilustración 2. Mala conficion que haze los padres. Guaman Poma, Nueva coronica (1615). estuvo determinada por la escasez de testimonios indígenas -las mujeres indias raras veces acudían a denunciar a los curas solicitantes- pero también por la invisibilización de los testimonios nativos en el curso de la propia práctica historiográfica.

En relación con la participación judicial de las mujeres indígenas, tanto en calidad de testigos como de denunciantes, los estudios pertinentes al tema permiten observar un impacto variable a lo largo del período de actividad inquisitorial. Según Asunción Lavrin, durante el último cuarto del siglo XVI, las mujeres indígenas novohispanas fueron el objetivo principal de los confesores, mientras que una vez entrado el siglo XVII se observa una reorientación de sus actos carnales hacia mujeres de origen mestizo o peninsular (Lavrin 2004: 295). Esa tendencia parece confirmarse en la investigación de Jorge René González (2002: 212-213) quien revela que, durante el siglo XVIII y la primera década del XIX, las indígenas representaron apenas el 5\% de las mujeres solicitadas, mientras que las criollas alcanzaron el $45 \%$. Si bien el autor señala que la escasez de denuncias indígenas debe atribuirse a las dificultades que este colectivo tuvo para acceder a la justicia (González Marmolejo 1985: 79), deberíamos interrogarnos qué cambios se produjeron respecto del período anterior, teniendo en cuenta que, hasta las primeras décadas del siglo XVII, los testimonios documentados parecen sugerir que las mujeres indígenas accedieron con mayor asiduidad a la instancia judicial.

En el caso peruano, la temprana presencia de mujeres indígenas en los tribunales inquisitoriales ya había sido señalada por José Toribio Medina (1945: 126-129) quien advertía al público lector, con la prudencia y la moderación del caso, acerca de cierta afición de los doctrineros del Tucumán por solicitar a mujeres de origen nativo. Los estudios posteriores acerca del tema, aunque escasos, recogieron este sesgo de la documentación pero sin contextualizar ni problematizar el significado de esta marcada presencia indígena, especialmente en las primeras cuatro décadas de actuación inquisitorial. Ana Sánchez, en un trabajo pionero en relación con el tema, corrobora el hecho de que la inquisición peruana recibió "multitud de denuncias" de mujeres indias aunque, en su opinión, los inquisidores no procedieron con determinación contra los solicitantes por considerar que las testificaciones nativas carecían de crédito (Sánchez 1996: 134). Mediante un estudio pormenorizado de las 
relaciones de causa, René Millar Carvacho ofrece una aproximación cuantitativa a esa "multitud de denuncias". Según el autor, durante todo el período de actuación inquisitorial (1570-1820), las indias representaron el $61 \%$ de las mujeres solicitadas en confesión (Millar Carvacho 1997: 357), es decir, un porcentaje más que considerable. Lamentablemente, al no estar la información desagregada por años o períodos, resulta difícil trazar una periodización semejante a la novohispana. Sabemos, por la presente investigación, que durante los siglos XVI y XVII, las causas seguidas contra "solicitantes de indias" representaron casi el 50\% del total de los casos, concentrándose todos ellos entre 1571 y $1610^{6}$; pero desconocemos cuál fue el impacto de la presencia judicial indígena durante el siglo XVIII y la primera década del XIX ${ }^{7}$. En cualquier caso, debemos tener en cuenta que los testimonios conservados documentalmente no deben interpretarse como un correlato de la práctica de la solicitación, sino, más bien, como el resultado de un conjunto de circunstancias específicas y contextualizadas.

No obstante, para el período que aquí nos ocupa, se observa un alto protagonismo indígena en las causas seguidas por solicitación. Sin embargo, los testimonios de las mujeres indias raramente son incorporados como objeto de análisis en los estudios pertinentes al tema. Una excepción puede constituir el trabajo de René Millar Carvacho quien recupera las declaraciones indígenas, si no para indagar en sus modulaciones discursivas específicas, al menos para observar el modo en que sus testimonios fueron tratados por los magistrados inquisitoriales (Millar Carvacho 1999: 142-146).

Las relaciones de causas conservan fragmentos de esos testimonios, aunque no de manera directa ni inmediata. Las voces de las mujeres indígenas fueron objeto de múltiples mediaciones que procedieron tanto de su condición jurídica como de las características del soporte judicial en el que se registraron sus declaraciones.

En relación con este último problema, es importante notar que los testimonios indígenas fueron el resultado de un complejo proceso de composición. Debido a que las indias que testificaron en las causas por solicitación lo hicieron en sus lenguas originarias, un primer momento estuvo determinado por la "traducción" de sus declaraciones, por lo general, a cargo de un mestizo o un indio ladino que oficiaba de intérprete (Aguilar 2002: 149-150). Uno de los principales problemas que suscitó la interpretación fue la tergiversación de los testimonios originales tanto por malentendidos involuntarios como por manipulaciones deliberadas. En efecto, el intérprete que intervino en la causa incoada en 1598 contra Diego de Sanabria, reconoció ante los inquisidores que su interpretación había sido inducida por el fraile con el objetivo de alterar las testificaciones de las indias en su favor persuadido de que, de este modo, "el testigo hacia con ello servicio a Dios" 8 . Otra de las dificultades que supuso la instancia de interpretación fue la estandarización de las declaraciones de los testigos derivada del hecho de que una misma persona solía ser la encargada de llevar a cabo la traducción. En las causas de los "solicitantes del indias", especialmente aquellas que cuentan con un número elevado de testigos, es posible observar la uniformidad de los testimonios. El notario que resumió el proceso incoado contra Diego de Ruiz en 1600 transcribió las declaraciones de las primeras 19 testigos de las 56 que fueron ratificadas. El oficial fundaba esta decisión administrativa en el hecho de que "los demas testigos de la solicitación dizen todos de la mesma manera y casi por las mesmas palabras que han dicho los que van declarados porque todas las yndias declaran por ynterprete" 9 .

Un segundo momento del proceso de composición de los testimonios estuvo dado por la "transcripción" de la interpretación a cargo del notario. Esta instancia significó la subsunción de la declaración oral en un formato legal escrito. Si bien en el marco de este procedimiento pudieron cristalizarse los errores derivados de la traducción, también es posible que haya contribuido a corregir algunos "excesos" de la interpretación, ya que muchos de ellos estaban instruidos en las lenguas vernáculas (Presta 2013: 352-354). En efecto, los oficiales que informaron a los inquisidores generales acerca de la actuación del tribunal en las causas de solicitación a mujeres indígenas, señalaban que, además de los intérpretes, los notarios que presenciaron y registraron la examinación "savian tamvien muy bien la lengua" 10 . Sin desestimar las alteraciones que estos oficiales pudieron introducir en el ejercicio de su tarea, una mención especial merece la adaptación de las declaraciones a los formulismos jurídicos de los que se nutrió la práctica judicial. El formato legal no solo encapsuló los testimonios originales, sino que tendió a reforzar la estandarización y reiteración textual de las testificaciones (Oyarzabal 2016: 4-5). 
Las relaciones de causas añadieron un momento adicional de composición que tuvo lugar cuando el oficial que debía informar lo actuado al Consejo de la Suprema y General Inquisición resumía la causa original ${ }^{11}$. Este momento suponía una mediación adicional entre los testimonios enunciados y los registrados, en la medida en que las relaciones no asentaban las declaraciones textuales sino paráfrasis de las mismas. El proceso de abreviación de la causa implicó la pérdida del testimonio directo cuando no de la identidad de las declarantes. Solo en contadas ocasiones ellas aparecen con sus nombres de pilas, mientras que en la mayoría de los casos lo hacen de manera anónima, apenas referenciadas por su estado civil o su edad -"Otro testigo muger casada yndia mayor de hedad"- o precedida por un número que indicaba el orden de testificación (Ilustración 3).

La doble minoridad jurídica de la que fueron objeto las declarantes -en tanto mujeres y en tanto indígenas- también condicionó el carácter de los testimonios registrados. Aun cuando la administración colonial ofreció herramientas que permitieron a los indígenas acceder a la justicia, el estatuto de miserabilidad y rusticidad bajo la que lo hicieron tendió a devaluar sus testificaciones en el marco de los procesos judiciales (Cunnil 2011: 240-241) ${ }^{12}$. El jurista Juan de Solórzano Pereira consideraba que debía excusarse a los indígenas de juramentar en sus pleitos en virtud del perjuro en el que podían incurrir, ya que "no hacen bastante concepto de la fuerça del juramento, ni de la obligacion de dezir verdad" (Solórzano Pereira 1703 [1629-1639]: 122). Los estereotipos raciales que calificaron a los indios de "mendaces y mentirosos" contribuyeron al reforzamiento de esa tendencia. En las instrucciones a los visitadores de los pueblos de indios, el virrey Francisco de Toledo advertía a los oficiales de la visita acerca de la inclinación de los indígenas hacia el falso testimonio, por lo que ordenaba que en los pleitos de indios no se considerara ni se examinara a los testigos de esa condición. En caso de tener que recurrir a sus testificaciones, el virrey formulaba una peculiar aritmética, según esta, en causas graves, debían citarse al menos seis testigos indígenas aunque "no se les de[bía dar] mas fe y crédito que si solo uno idóneo se hubiera examinado" (Solórzano Pereira 1703 [1629-1639]: 122) ${ }^{13}$.

La condición femenina de las testigos también influyó en la composición de sus declaraciones. Según las doctrinas jurídicas de la época, la flaqueza, volubilidad e incapacidad intelectual femeninas suponían un obstáculo para que las mujeres pudieran intervenir en la esfera judicial en calidad de testigos "graves", en la medida en que sus testimonios, como los de los menores y los rústicos, eran considerados poco fiables (Hespanha 2001: 81-82, 86). En las causas seguidas por solicitación -cuyos testigos fueron principalmente mujeres- los inquisidores generales instruyeron a los magistrados limeños para que solo procedieran a la captura del reo si disponían de dos testigos fidedignos que concluyeran la comisión del delito ${ }^{14}$. Esta disposición venía a corregir el procedimiento que hasta entonces habían seguido los magistrados locales, incoando causas contra curas solicitantes a partir de un único testimonio. Asimismo, en relación con la "calidad" de las declarantes, los inquisidores generales recomendaban tener en cuenta si se trataba de "mugeres desonestas o apasionadas" y, en tal caso, sugerían cotejar sus testimonios con los de "personas graves y sin sospecha" 15 . Este conjunto de instrucciones ponían de manifiesto la desconfianza y el recelo que despertaban los testimonios femeninos, los que fueron puestos a prueba por los magistrados en el marco de su práctica judicial (Alejandre 1999: 174).

\section{Polifonías indígenas: entre el desprestigio indígena y la desestabilización del orden colonial}

El tratamiento del que fueron objeto las indias que oficiaron de testigos en los juicios por solicitación permite observar cómo la cadena de significantes que enlazaba las nociones de minoridad, feminidad e indianidad propició el desprestigio de sus declaraciones ${ }^{16}$. El análisis de las relaciones de causas revela que, durante los primeros años de actuación del tribunal, los inquisidores limeños fueron renuentes a considerar las denuncias de las mujeres indígenas. La causa iniciada en 1576 contra fray Baltazar de la orden de Nuestra Señora de la Merced, cura de la doctrina de Picoaza en Puerto Viejo, ofrece algunas pistas al respecto. En conformidad con el juez ordinario y los consultores, el 7 de mayo de 1578, los inquisidores Cerezuela y Gutiérrez de Ulloa votaron dar noticia a la Suprema de que no procederían a la examinación de los testigos debido a que todos eran indígenas. Los motivos del dictamen se fundaban en

que tenemos a los yndios e yndias por tan poca fe y crédito que nos paresce que por 


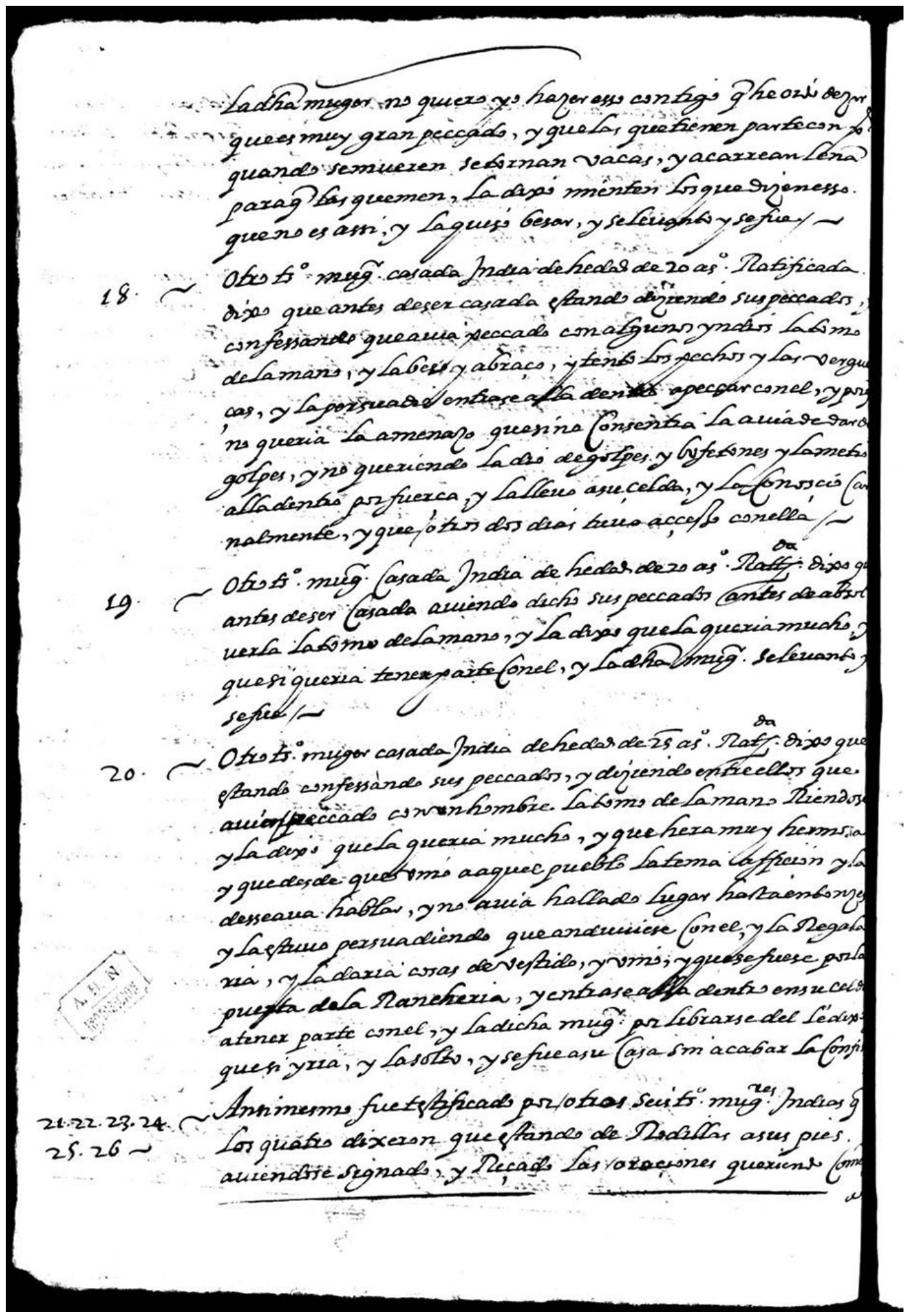

Ilustración 3. Relación de las testificaciones de mujeres indígenas. AHN, Inquisición, Libro 1029, f. 86v. (1599). 
sus dichos aunque sean muchos no se puede proceder a castigo en casos tan graves como los que se tratan en la ynquisicion y asi aunque a avido algunas denunciaciones de yndias (...) no procedemos con tales testigos ni examinaremos las yndias a quienes an solicitado ${ }^{17}$.

En estos casos, las causas se determinaron a partir del testimonio de otros testigos o de la propia confesión del reo. Incluso, en aquellos casos donde las declaraciones de las indígenas coincidían con las de los acusados u otros testigos fidedignos, los magistrados proseguían la instrucción sin tomar en consideración sus testificaciones.

Sin embargo, hacia finales de la década del setenta, la praxis judicial parece haber tomado otro curso. A partir de entonces, las testificaciones de las mujeres indígenas fueron incorporadas a las causas judiciales como pruebas con valor legal. El cambio de política estuvo motivado por las dificultades que presentaban aquellas causas cuyas testificaciones procedían únicamente de mujeres indígenas. Con el fin de remediar esa situación, mediante una carta emitida el 9 de diciembre de 1583, la Suprema instruía a los inquisidores limeños para que tomaran en consideración los testimonios de las indias solicitadas, aunque recomendaba reunir un número importante de testigos contestes y "entender su trato y modo de vivir" (Millar Carvacho 1999: 145). Es probable que la disposición de los inquisidores generales formalizara una práctica judicial que los magistrados locales venían desarrollando de manera irregular, ya que, según se puede colegir del análisis de la documentación, las indias comenzaron a ser examinadas algunos años antes de esa disposición.

No obstante, ese cambio en la política testimonial no supuso una apreciación de las voces indígenas. Una de las principales estrategias judiciales de los acusados consistió en desestimar la imputación del delito, aludiendo justamente a la condición jurídica de las testigos. La rusticidad y la falta de entendimiento fueron los principales argumentos con los que basaron sus alegatos. El dominico Juan Angulo de Cabrera, procesado en 1582, se defendió de las acusaciones argumentando que los tocamientos que había tenido con algunas de sus penitentes no habían sido con mala intención -como ellas erróneamente interpretaron- sino que las "tomo de las manos estandola[s] confesando porque son tan bestias que no saben ponerlas y estan jugando con las manos"18. Una defensa similar articuló el mercedario Alonso Díaz quien, en 1597, fue testificado por más de 40 indias de haberlas solicitado. Si bien en su confesión admitía haberlas tomado de las manos e incluso acariciado el rostro en el marco de la penitencia, explicaba que lo había hecho sin malicia aunque "las dichas yndias como gente facil [debieron] aver pensado que se les decía con mal yntento y con propósito de pecar con ellas carnalmente" 19 .

Otro de los argumentos con el que los reos procuraron desestimar las declaraciones indígenas se basó en su "natural" docilidad y sumisión que las convertía en objeto de manipulación por parte de terceros. En la causa seguida contra Melchor Maldonado, doctrinero de Chiquiligasta en la provincia de Tucumán, el fraile denunciaba que las acusaciones que las indias pusieron en su contra habían sido motivadas por el comisario de la Inquisición del distrito. Según le confiaron unos indios de su doctrina, el comisario había examinado intencionalmente a las indias acerca de si el reo había tenido actos propincuos a la solicitación "y que de temor havian dicho que si" ${ }^{20}$. Juan de Baldivieso, cura de la doctrina de Chachapoyas, atribuía las denuncias de las que fue objeto a ciertas desavenencias que había tenido con algunos particulares. En ese escenario, los inquisidores no debían dar crédito a las declaraciones de las testigos, en la medida en que "eran falsos testimonios y que eran yndias persuadidas de sus encomenderos" 21 . La misma estrategia diseñó el clérigo Juan de Salcedo quien, ante las denuncias recibidas en 1598 por las indias de su doctrina, sindicó a algunos españoles de la provincia de Tucumán como los responsables de haber "inducido a las yndias a que dixesen mal de el" 22 . Esta serie de alegatos empalmó con la doctrina jurídica del indio miserable, según esta, "su humilde, servil y rendida condicion", los inclinaba a testificar, persuadidos o instruidos por otras personas o bien para satisfacer los requerimientos de los magistrados (Solórzano Pereira 1703 [16291639]: 122).

El análisis de la documentación permite observar que la actuación de los inquisidores también se ordenó a partir de las nociones de mendacidad y miserabilidad mencionadas. En la causa seguida contra el citado Juan de Baldivieso, los magistrados lo condenaron a que abjurase de levi en la sala de audiencias, lo privaron perpetuamente de confesar mujeres y lo desterraron de la provincia de Chachapoyas por el 
tiempo de cuatro años, además de imponerle penas menores, como decir misas por las ánimas del purgatorio y rezar la tercera parte del rosario durante un año. La condena recibida resultaba relativamente benigna si se tiene en cuenta que, de ordinario, los inquisidores solían aplicar la privación perpetua para confesar a mujeres y a varones, disciplinas públicas o privadas y, lo más importante, la lectura de la sentencia frente a los prelados, curas y confesores de la ciudad ${ }^{23}$. Los jueces fundaron su sentencia en la hipótesis de que los encomenderos pudieron haber persuadido a las testigos para que declararan en su contra, aun cuando no tenían pruebas ni indicios para confirmarla. En cualquier caso, consideraron que "por ser yndias parecio a la consulta que hera suficiente pena la que se le dava"24.

Una resolución similar rubricaron en las causas de los franciscanos Juan Prieto, Bartolomé de la Cruz y Andrés Corral, doctrineros de la provincia de Tucumán, procesados en 1599 por haber solicitado a varias indias en el acto de la confesión. En esta oportunidad, los magistrados consideraron conveniente no leer la condenada delante de sus hermanos de religión, en virtud de la calidad de los testimonios que habían dado lugar a su sentencia. En su opinión, las indias que habían testificado en contra de los frailes no solo eran "gente muy facil y mentirosa y que a quelquiera cosa que los quieran ynducir le hacen", sino que en aquellos confines se trataba, además, de "gente desnuda y muy barbara" 25 .

La moderación de las condenas estuvo motivada por el hecho de que los acusados jamás reconocieron los cargos que se les imputaban, ni sobrevinieron testigos "idóneos" que pudieran respaldar las devaluadas testificaciones indígenas. El mismo escenario testimonial llevó en otras oportunidades a dictar directamente la absolución de los reos o a la suspensión de las causas como en los casos de los clérigos Juan de Padilla, Pedro de Victoria y Pedro Rodríguez de Padilla, encauzados en 1576, 1596 y 1598 por el tribunal, respectivamente ${ }^{26}$. En la causa seguida contra este último, los magistrados resolvieron suspender el proceso "por no tener mas de dos mugeres yndias ratificadas en el acto de la confesión, menores", así como por no estar lo suficientemente convencidos de la veracidad de sus testimonios ${ }^{27}$.

No obstante, en la medida en que los inquisidores tenían la responsabilidad de administrar justicia, en muchas oportunidades, la práctica judicial exigió tomar en consideración las voces de estas mujeres. Un acercamiento cuantitativo a la documentación permite observar que, de las 43 causas tramitadas entre 1571 y 1610 contra "solicitantes de indias", solo en 3 de ellas se procedió a la absolución del reo y en 5 se suspendió el proceso, mientras que en 31 casos los acusados fueron hallados culpables recibiendo como castigo diversas penas arbitrarias ${ }^{28}$. Estos datos discuten la afirmación de Ana Sánchez de que los inquisidores no habrían procedido con determinación contra los solicitantes de indias, como quedaría demostrado, según la autora, en el hecho de que "buena parte de los curas denunciados por ellas fueron absueltos o vieron suspendido el proceso" (Sánchez 1996: 134).

¿Qué lugar ocuparon los testimonios indígenas en la formulación de estas sentencias? Como mencionáramos, el descrédito que despertaban las testificaciones de las indias solicitadas incitó a algunos magistrados a contemplar ciertas prerrogativas en favor de los reos; sin embargo, en otras ocasiones, se mostraron proclives a considerarlas. En 1601, los jueces que instruyeron los procesos de varios curas en la provincia de Tucumán concluían que, aunque las indias eran fáciles, mendaces y persuasibles, "la esperiencia ha enseñado que han dicho verdad (...) porque los mas de los reos han confesado" 29 . De este modo, los jueces se encontraban en una situación paradojal: si por un lado estaban influenciados por las doctrinas de la miserabilidad indígena, por otro lado su propia práctica judicial revelaba una realidad diferente. A pesar de eso, los prejuicios raciales y de género jurídicamente sancionados se sobrepusieron a la evidencia, ya que otorgaron veracidad a los testimonios indígenas siempre que estuvieran respaldados por la palabra de un interlocutor calificado. En la causa incoada contra el agustino Alonso de Mendoza en 1594, las indias que depusieron en su contra fueron llamadas a testificar luego de que un grupo de testigos "graves", entre los que se contaban varios frailes y legos españoles, declararon de oídas que el reo solicitaba a las indias de su doctrina ${ }^{30}$. Un procedimiento similar se implementó en el caso del clérigo García de Torres, cuya causa fue instruida en 1600 a raíz de una denuncia que el rector de la Compañía de Jesús de la ciudad de Córdoba presentó ante el comisario de la jurisdicción ${ }^{31}$. Según el testigo, predicando en una doctrina de indios aledaña a la ciudad, dos mujeres le habían dado noticia de cómo García de Torre solicitaba a las indias en el acto de la confesión y le rogaban que diera aviso 
al comisario, ya que ellas no se atrevían a hacerlo. Es posible que el recelo de las indias a acudir a la justicia no solo estuviera motivado por el temor a los castigos que el clérigo pudiera infringirles como escarmiento, sino también a la sospecha de que sus denuncias no fueran consideradas por los magistrados. Los casos citados ponen de manifiesto que, para la administración de justicia, el peso de la prueba no estuvo puesto tanto en qué se decía sino en quién lo hacía, especialmente si se tiene en cuenta que todas las declaraciones compartían la misma fuente de información, a saber, los "dichos" de las indias solicitadas. En ese sentido, podemos sugerir que las voces de las mujeres indígenas solo cobraron fuerza legal en la medida en que fueron intermediadas por voces "autorizadas".

No obstante, la palabra de estas mujeres constituyó también un desafío para muchos curas doctrineros $\mathrm{y}$, en ese sentido, fueron una fuente potencial de desestabilización de las relaciones de poder. Como mencionáramos, los mecanismos de dominación que articularon la vida en las doctrinas no siempre fueron eficaces para obliterar las denuncias indígenas. En muchas ocasiones, los doctrineros debieron recurrir a estrategias que iban más allá del escarmiento o su amenaza, con el fin de concitar el silencio de las víctimas. Una de ellas consistió en apelar a la clemencia, especialmente cuando las penitentes se habían sentido ofendidas o agraviadas por los requerimientos amorosos realizados por sus padres de confesión. Una de las principales preocupaciones, en estos casos, fue que las indias, afligidas por descargar su conciencia, acudieran a confesarse con otros curas, poniendo al descubierto la falta cometida. María Chimbo, natural de Chinchero y residente en el pueblo de Maras, testificó que, luego de haber sido solicitada por Lorenzo López Barriales, de la Compañía de Jesús, en la cuaresma de 1593, el fraile le había suplicado que no comunicase a ningún otro confesor lo que había sucedido ya "que el avia hecho mal y merecia gran penitencia por el pecado que avia cometido de solicitarla y que le daría quentas benditas" 32 . Las mismas súplicas realizaron los padres Juan de Figueroa y Diego de Chávez quienes procuraron compensar la discreción de las indias de sus doctrinas con el otorgamiento de la absolución de sus pecados, eximiéndolas de su deber de denunciarlos como señalaban las instrucciones ${ }^{33}$.

Los ruegos solían ser mayores cuando las denuncias indígenas podían llegar directamente a las autoridades competentes, en este caso, a los comisarios o a los magistrados del Santo Oficio. Dos indias que testificaron en la causa de Bartolomé de la Cruz declararon que, antes de emprender el camino a la ciudad de Los Reyes para comparecer ante los inquisidores, el fraile "las dixo y rogo mucho" que no dieran información alguna al comisario de la jurisdicción ${ }^{34}$. Del mismo modo procedió Diego de Sanabria quien "les rogava mucho" a las testigos que no acudieran al llamado del oficial inquisitorial y, en caso de hacerlo, "no dixesen contra el ni contra algun religioso de su orden" ${ }^{35}$. Por lo general, los ruegos solían ir acompañados de promesas de beneficios materiales como dinero, ropa, maíz y hasta chacras con los que los confesores buscaban obtener la complicidad de las penitentes ${ }^{36}$. ¿En qué medida estas estrategias disuadieron a las indias de comparecer ante los magistrados? Sabemos que desde épocas muy tempranas las poblaciones indígenas acudieron a la justicia para denunciar los abusos cometidos por los corregidores, encomenderos, doctrineros y otros agentes coloniales, así como para dirimir conflictos entre indios, lo que les valió el epíteto de "pleitistas" (Poloni-Simard 2005: 177-178; Honores 2003: 1) (Ilustración 4).

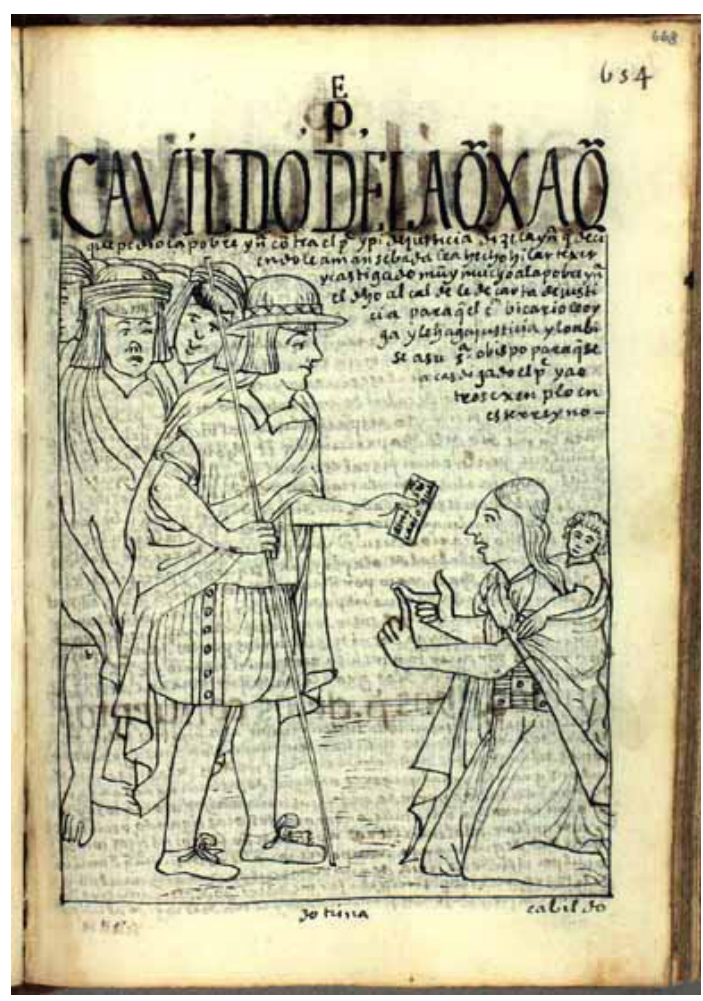

Ilustración 4. Cavildo de la queja que haze la pobre yndia contra el padre. Guaman Poma, Nueva coronica (1615) 
Lamentablemente, la documentación disponible no nos permite elaborar una respuesta concluyente al respecto. Sin embargo, es posible que las mujeres indígenas utilizaran ese "saber hacer" en su beneficio del mismo modo que, en el curso de las causas, manipularon sus testimonios, ya sea retractándose, alterándolos o ratificándolos.

\section{Consideraciones finales}

El análisis de las relaciones de las causas de fe que el Santo Oficio limeño tramitó contra los denominados curas solicitantes permite observar la ambiguiedad que suscitó la palabra de las mujeres indígenas en el curso de la praxis inquisitorial. Si por un lado las doctrinas jurídicas de la época tendieron a descartar o subestimar los testimonios indígenas, fundándose en la "calidad" de quienes testificaban, por otro, la práctica judicial no pudo prescindir por completo de ellos. Aun cuando las declaraciones de las indias solicitadas fueron permanentemente auditadas, los magistrados se vieron obligados a apelar a ellas con el fin de fulminar muchas de las causas de fe.

Asimismo, a pesar del descrédito social del que fueron objeto, las voces indígenas representaron una fuente de desestabilización al orden social. El despotismo con el que los doctrineros solían ejercer su autoridad en los pueblos de indios encontró su límite allí donde esas voces podían adquirir valor legal. Las estrategias consensuales que los doctrineros articularon con el objetivo de concitar la complicidad de sus víctimas, no solo ponían de manifiesto la insuficiencia de los mecanismos de coerción, sino también la potencialidad de los testimonios nativos para desafiar, en determinados contextos, las relaciones de poder.

En lo que respecta a la participación judicial de las mujeres indígenas, si bien es cierto que lo hicieron en condiciones evidentemente desfavorables, no es menos cierto que la arena judicial les ofreció un espacio propicio para canalizar sus denuncias y reclamaciones. La documentación analizada revela que las causas por solicitación no tuvieron a las indias como sus principales litigantes -en general los procesos se iniciaron de oficio, por autoinculpación o por denuncia de un testigo "grave"-. Sin embargo, permite observar un hábil desempeño como testificantes, así como un conocimiento de los efectos que su palabra podía generar al pronunciarse en el estrado.

El tratamiento que los magistrados -pero también los acusados-dieron a los testimonios de las mujeres indígenas, así como el modo en que ellas intervinieron judicialmente, empalmó con el carácter contradictorio de la justicia colonial, esto es, como una instancia donde se expresó y refrendó el ordenamiento jerárquico de la sociedad, pero también como un espacio de participación, disputas y negociaciones.

\section{Referencias Citadas}

1585 Confesionario para los curas de indios compuesto y traducido en las lenguas quichua y aymara por autoridad del Concilio Provincial de Lima del año 1583. Con licencia de la Real Audiencia de la ciudad de los Reyes por Antonio Ricardo, Los Reyes.

Acosta, A.

2014 "Los clérigos doctrineros y la economía colonial, Lima, 1600-1630”. En Prácticas coloniales de la Iglesia en el Perú. Siglos XVI-XVII, compilados por Nicanor Domínguez, pp. 163-197. Aconcagua/IEAL, Sevilla, España.

Aguilar, M.

2002 "The indio ladino as cultural mediator in the Colonial society”. Estudios de Cultura Náhuatl 33: 149-150, Instituto de Investigaciones Históricas de la Universidad Nacional Autónoma de México.

Alberro, S.

1988 Inquisición y Sociedad en México, 1571-1700. Fondo de Cultura Económica, México.

Alejandre, J. A.

1994 El veneno de Dios. La inquisición de Sevilla ante el delito de solicitación en confesión. Siglo XXI Editores, Madrid.
Ares Queija, B.

2004 "Mancebas de españoles, madres de mestizos: imágenes de la mujer indígena en el Perú colonial temprano". En: Las mujeres en la construcción de las sociedades iberoamericanas, editado por Pilar Gonzalbo Aizpuru y Berta Ares Queija, pp. 15-40. Escuela de Estudios HispanoAmericanos, Sevilla, España.

Cunill, C.

2011 "El indio miserable: nacimiento de la teoría legal en la América colonial del siglo XVI". Cuadernos Inter.c.a.mbio sobre Centroamérica y el Caribe 9: 229-248, Centro de Investigación en Identidad y Cultura Latinoamericanas de la Universidad de Costa Rica.

Estenssoro Fuchs, J. C.

2003 Del paganismo a la santidad. La incorporación de los indios del Perú al catolicismo. 1532-1750. IFEA, Lima, Perú.

Foucault, M.

2006 [1977] Historia de la sexualidad. Vol. 1.La voluntad del saber. Siglo XXI Editores, Buenos Aires, Argentina. 
González Marmolejo, J. R.

2002 Sexo y confesión. La Iglesia y la penitencia en los siglos XVIII y XIX en la Nueva España. Plaza y Valdés Editores/ Instituto Nacional de Antropología e Historia, México.

González Marmolejo, J. R.

1985 "Pecados virtuosos. El delito de solicitación en la Nueva España (siglo XVIII)". Revista Historias 11: 73-83, Instituto Nacional de Antropología e Historia, México.

Griffiths, N.

1998 La cruz y la serpiente. Fondo Editorial PUCP, Lima, Perú.

Gruzinski, S.

1991 "Aculturación e individualización: modalidades e impacto de la confesión entre los indios nahuas de México. Siglos XVI-XVIII". En: Sexualidad y matrimonio en la América Hispánica. Siglos XVI-XVII, coordinado por Asunción Lavrín (coord.), pp. 105-126. CONACULTA-Grijalbo, México.

Guaman Poma de Ayala, F.

1615 El primer nueva corónica y buen gobierno. (http:// www.kb.dk/permalink/2006/poma/titlepage/es/ text/?open=idp23904)

Haliczer, S.

1998 Sexualidad en el confesionario. Un sacramento profanado. Siglo XXI Editores, Madrid, España.

Hespanha, A. M.

2001 "El estatuto jurídico de la mujer en el Derecho común clásico". Revista jurídica de la Universidad Autónoma de Madrid 4: 72-87. Universidad Autónoma de Madrid, España.

Honores, R.

2007 "Los caciques y las pruebas: El uso de las testimoniales en las disputas por cacicazgos en la Audiencia de Lima, 1550-1610". XI Jornadas Interescuelas/Departamentos de Historia. Departamento de Historia de la Facultad de Filosofía y Letras, Universidad Nacional de Tucumán, San Miguel de Tucumán, Argentina.

Honores, R.

2003 La asistencia jurídica privada a los señores indígenas ante la Real Audiencia de Lima, 1552-1570. http://lasa. international.pitt.edu/Lasa2003/HonoresRenzo.pdf

Lavrin, A.

2004 "Los hombres de Dios: Aproximación a un estudio de la masculinidad en Nueva España". Anuario Colombiano de Historia Social y de la Cultura 31: 283-309. Departamento de Historia de la Universidad Nacional de Colombia.

Lisi, F.

1990 El Tercer Concilio Limense y la aculturación de indígenas sudamericanos. Universidad de Salamanca, Salamanca, España.

Mateos, F. (ed.)

1944a Historia general de la Compañia de Jesús en la provincia del Perú. Tomo I. Consejo Superior de Investigaciones Científicas e Instituto Gonzalo Fernández de Oviedo, Madrid, España.

Mateos, F. (ed.)

1944b Historia general de la Compañía de Jesús en la provincia del Perú. Tomo II. Consejo Superior de Investigaciones Científicas e Instituto Gonzalo Fernández de Oviedo, Madrid, España.
Medina, J. T.

1945 La Inquisición en el Río de la Plata. El tribunal del Santo Oficio de la Inquisición en las Provincias del Plata. Editorial Huarpes, Buenos Aires, Argentina.

Medina, J. T.

1944 El tribunal del Santo Oficio de la Inquisición en las Provincias del Plata. Editorial Huarpes, Buenos Aires, Argentina.

Medina, J. T.

1887 Historia del Tribunal del Santo Oficio de la Inquisición de Lima (1569-1820). Tomo 1. Imprenta Gutenberg, Santiago de Chile.

Millar Carvacho, R.

1999 La Inquisición de Lima y el delito de solicitación. En La Inquisición en Hispanoamérica, editado por Abelardo Levaggi, pp. 105-208. Ediciones Ciudad Argentina, Buenos Aires, Argentina.

Millar Carvacho, R.

AÑO Inquisición y sociedad en el Virreinato del Peruano. Instituto Riva Agüero/Pontificia Universidad Católica de Chile, Lima, Perú.

Molina, F.

2017a Cuando amar era pecado. Sexualidad, poder e identidad entre los sodomitas coloniales (Virreinato del Perú, Siglos XVI-XVII). IFEA/Plural Editores, Lima/La Paz, Perú/Bolivia.

Molina, F.

2017b "Casadas dos veces. Mujeres e inquisidores ante el delito de bigamia femenina en el Virreinato del Perú (Siglos XVI-XVII)". Memoria Americana. Cuadernos de Etnohistoria vol.25, $\mathrm{n}^{\circ} 1$ : 31-46. Instituto de Ciencias Antropológicas, Facultad de Filosofía y Letras de la Universidad de Buenos Aires, Argentina.

Oyarzábal, M. C.

2016 'La palabra de los ‘naturales' en la justicia. Posibilidades y limitaciones en el análisis de la documentación judicial referida a indígenas (Jujuy, siglo XVII)". Trabajos y comunicaciones 43, Facultad de Humanidades y Ciencias de la Comunicación, Universidad Nacional de La Plata, Argentina.

Owensby, B. P.

2011 "Pacto entre rey lejano y súbditos indígenas. Justicia, legalidad y política en Nueva España, siglo XVII". Historia Mexicana vol. 61, No 1 (241): 59-106. Colegio de México.

Poloni-Simard, J.

2005 "Los indios ante la justicia. El pleito como parte de la consolidación de la sociedad colonial". En Máscaras, Tretas y rodeos del discurso colonial en los Andes, editado por Bernard Lavallé, pp. 177-188. IFEA/Instituto Riva-Agüero, Lima, Perú.

Presta, A. M.

2013 "Redes de tinta y poder. Escribanos, clero e indígenas en la ciudad de La Plata, siglos XVI-XVII". Anuario de Estudios Bolivianos, Archivísticos y Bibliográficos 19: 352-354. Archivo y Biblioteca Nacionales de Bolivia.

Sánchez, A.

1996 "Pecados secretos, públicas virtudes: el acoso sexual en el confesionario". Revista Andina 14, No 1: 121-147. Centro de Estudios Regionales Andinos "Bartolomé de Las Casas", Cusco, Perú. 
Sarrión Mora, A.

2010 Sexualidad y confesión: la solicitación ante el tribunal del Santo Oficio (siglos XVI-XIX). Ediciones de la Universidad de Castilla-La Mancha, Cuenca, España.

Solórzano Pereira, J. de.

1703 [1629-1639] Política Indiana. Henrico y Cornelio Verdussen, Amberes.

Valadés, D.

1579 Rhetorica christiana: ad concionandi et orandi vsvm accommodata, vtrivsq[ue] facvltatis exemplis svo loco insertis: qvae qvidem ex Indorvm maximè deprompta svnt historiis: vnde praeterdoctrinam, svma qvoqve delectatio comparabitvrs. Petrus Jacobus Petrutius, Perugia.

Valenzuela Márquez, J.

2007 "Confesando a los indígenas. Pecado, culpa y aculturación en América colonial". Revista Española de Antropología
Americana 37: 39-59. Universidad Complutense, Madrid, España.

Vargas Ugarte, R.

1990 Concilios Limenses (1551-1772). Tomo I. Juan Cardenal Guevara, arzobispo de Lima, Lima, Perú.

Vassallo, J.

2009 "Algunas notas sobre sacerdotes solicitantes y amancebados en Córdoba del Tucumán durante el siglo XVIII". Tiempos modernos 19 (2): 1-24. Asociación Tiempos Modernos, España.

Wiesner-Hanks, M. E.

2001 Cristianismo y sexualidad en la edad moderna: la regulación del deseo, la reforma de la práctica. Siglo XXI Editores, Madrid, España.

Notas

1 Con el fin de subsanar algunos de los errores, los doctrineros andinos incentivaron el uso del quipu, esto es, un sistema nemotécnico de notación prehispánica basado en cuerdas anudadas, de modo que los indígenas pudieran acceder a una confesión correcta. El uso del quipu fue sancionado por el Tercer Concilio Limense que lo considerará un instrumento indispensable para el ordenamiento de los pecados. No obstante, hacia la segunda mitad del siglo XVII la práctica caerá en desuso y será visualizada como indicio de idolatría (Estenssoro Fuchs 2003: 217-227).

2 Archivo Histórico Nacional de Madrid (en adelante AHN), Inquisición, Libro 1028, f. 435v.

3 De las especies de la lujuria ver Molina (2017a: 27-32)

4 En su estudio acerca de la solicitación en el tribunal inquisitorial sevillano, Juan Antonio Alejandre (1994: 65) observa que la confesión de la penitente acerca de alguna inquietud o debilidad en materia sexual solía incitar a los confesores a solicitarlas para actos torpes.

5 AHN, Inquisición, Libro 1029, fs. 453-453v.

6 De los 88 curas solicitantes que comparecieron ante los tribunales inquisitoriales limeños durante los siglos XVI y XVII, 43 de ellos solicitaron a mujeres indígenas.

7 Trabajos específicos respecto de la comisaría de Córdoba del Tucumán, revelan que, durante el siglo XVIII, las indígenas estuvieron ausentes del colectivo de mujeres solicitadas (Vassalllo 2009: 10). Si bien el dato permitiría trazar una periodización semejante a la novohispana, antes de sacar conclusiones apresuradas, sería necesario realizar más estudios de casos allí donde se conserven sumarias elaboradas por los inquisidores locales o analizar sistemáticamente las relaciones de causas enviadas por los magistrados limeños a la Suprema con el propósito de determinar la adscripción racial de las mujeres solicitadas.

8 AHN, Inquisición, Libro 1029, f. 87v.

9 AHN, Inquisición, Libro 1029, f. 231.

10 AHN, Inquisición, Libro 1029, f. 334. Ver además AHN, Inquisición, Libro 1029, f. 231.

11 Las relaciones de causa eran compendios de los procesos incoados por los tribunales locales que, según las instrucciones, los inquisidores debían remitir al Consejo de la Suprema y General Inquisición dos veces al año con el objetivo de dar cuenta de lo actuado durante ese período (Medina 1887: 5). No obstante, en la práctica, los inquisidores limeños lo hicieron anualmente y, en algunas oportunidades, cada dos o más años según se pudo colegir del análisis de la documentación.

12 Brian P. Owensby (2011: 73-74) señala que la doctrina de la miserabilidad impulsada por la Corona tenía como propósito ofrecer a los indígenas herramientas judiciales para remediar los abusos de los que eran objetos aunque, en la práctica, sus efectos fueron limitados.

13 La política toledana seguía el espíritu del acuerdo celebrado por la Real Audiencia de Lima el 26 de abril de 1563, en el que establecía que el valor probatorio del testimonio de dos varones o tres mujeres indígenas equivalía al de un español (Honores 2007: 4).

14 La "Instrucción" que fue remitida a los inquisidores limeños el 26 de abril de 1577 era una copia de la enviada a los magistrados novohispano el 7 de abril del mismo año. AHN, Inquisición, Libro 352, fs. 109r y110r.

15 AHN, Inquisición, Libro 352, fs. 109.

16 En el capítulo sobre la miserabilidad indígena, el jurista Solórzano Pereira señala que los indios debían ser tratados jurídicamente del mismo modo que los menores y las mujeres en virtud de su rusticidad, miserabilidad y sumisión (Solórzano Pereira 1703 [1629-1639]: 123).

17 AHN, Inquisición, Libro 1034, f. 52.

18 AHN, Inquisición, Libro 1027, fs. 198-198v.

19 AHN, Inquisición, Libro 1028, f. 606v.

20 AHN, Inquisición, Libro 1028, f. 594v.

21 AHN, Inquisición, Libro 1028, f.597v.

22 AHN, Inquisición, Libro 1029, f. 225v.

23 Si bien los curas solicitantes estaban eximidos de salir al auto público de la fe -con el fin de evitar el escándalo entre los feligreses y preservar la dignidad del acusado-, sus condenas debían leerse ante todos los miembros del clero o de la orden según se tratara de un secular o un religioso. AHN, Inquisición, Libro 352, f. 109.

24 AHN, Inquisición, Libro 1028, f.597v.

25 AHN, Inquisición, Libro 1029, f. 83.

26 AHN, Inquisición, Libros 1027, fs. 63v-64 y 1028, fs. 541-542v y 598-598v. 
27 AHN, Inquisición, Libro 1028, f. 598v.

28 Las absoluciones y suspensiones representaron, en conjunto, el $19 \%$ del total de la muestra, mientras que las condenaciones ascendieron al $72 \%$; para 4 causas $(9 \%)$ no disponemos de información.

AHN, Inquisición, Libro 1029, f. 83v.

AHN, Inquisición, Libro 1028, f. 291.

AHN, Inquisición, Libro 1029, f. 332v-334.

AHN, Inquisición, Libro 1037, f. 275.

El Segundo Concilio Limense (1567-1568) estableció que los confesores de indios tenían la obligación de asentar en un libro a todos los indios e indias que habían cumplido con la confesión anual (Vargas Ugarte 1990: 247).
AHN, Inquisición, Libro 1029, f. 77.

AHN, Inquisición, Libro 1029, f. 87v.

36 Antonio Acosta (2014: 193) reveló prácticas similares en el contexto de las visitas eclesiásticas a las doctrinas de indios de la sierra central peruana. Con el fin de evitar las denuncias que sus feligreses podían interponer ante el juez visitador, los doctrineros solían recurrir al terror -mediante el uso de la violencia o la amenaza- o bien ganarse la confianza de los indios con regalos, beneficios económicos, morigeración de las cargas tributarias y laborales u otros "privilegios". 